\title{
Is it Time to separate Applied Science and Engineering?
}

\author{
F.A. Salustri, Ph.D., P.Eng \\ Ryerson University \\ salustri@ryerson.ca
}

\begin{abstract}
In this paper, the author proposes that the longterm health of engineering education in Canada would be served well by separating applied science and engineering. The rationale for such a separation is presented, along with some suggestions for how the two streams, each leading to a doctorate, could be implemented.
\end{abstract}

\section{Introduction}

I attended the 2003 CANCAM conference at the University of Calgary, and a number of the presentations and addresses brought to mind a matter I had thought of occasionally in the past: that a clearer separation of applied science and engineering is needed in Canadian academia. The confluence of ideas at this particular conference, however, has motivated me to consider this matter more seriously. In this article, I will try to express some of my thoughts on the subject, and stimulate discussion about a matter that I think is quite important.

At CANCAM, Prof. P.G. Glockner noted in his address a sharp decline in mechanics curriculum content over the past 50 years. He considered this a serious problem, and that without a return to stronger emphasis on mechanics in the curriculum, the overall capacity of (mechanical) engineers to conduct scientific work would decline.

The question is, however, does this scientific education actually help baccalaureate engineers practice engineering? Does an engineer with one University degree and who works in industry conduct scientific work? I do not believe so. While a good grounding in science is clearly necessary to appreciate the technical aspects of any engineering problem, it is only one of many components of expertise that a practicing engineer must have.
At the same conference, Dr. T. Brzustowski, president of NSERC, gave a keynote address in which he distinguished between three research activities of engineers. Basic research is the discovery and codification of new knowledge; project research is research directed at specific industry problems that cannot be solved solely with existent knowledge; and consulting is directed at solving specific industry problems that can be solved with only existent knowledge. This categorization provides a discrete spectrum of interrelation between engineering practice (as measured by the industry problems) and the "scientific" undertaking of knowledge discovery. As one moves from basic research through to consulting, knowledge discovery is attenuated.

It is interesting to note, however, that as knowledge discovery becomes attenuated, design practice becomes more significant. Let us set aside here notions of, say, design of research programs; instead, let us consider design in the sense of product design as engineers typically conduct it (the product being the outcome of the "project"). Basic research, then, need not contain any design elements at all; project research typically contains at least some design; and consulting may be entirely design.

There is a need for education in all three of these categories, as there continues to be many problems in all three categories requiring human resources investment. It is the obligation of universities to prepare students for entry into jobs that fall into at least one of these three categories. However, we have (especially at the undergraduate level) only one approach to engineering education: that currently sanctioned by the CEAB. There is no way that "one size fits all" here - there is no one educational format that can prepare students to work in any of the categories. In other words, we are not preparing our students well. 
In this article, I propose one way to address this problem.

\section{Further Details}

Over the last 15 years, I have taught at three Canadian universities and one American university. At all four institutions, I participated in various efforts to enhance, improve, update, or otherwise change the engineering curriculum at both the undergraduate and graduate levels. I came to notice that in all these efforts an underlying tension between two perspectives on curriculum change.

On the one hand is the need to provide students with a deep understanding of the science and mathematics of engineering, i.e. of the applied sciences, because they are the foundation of engineering. The applied sciences provide to students an understanding of the workings of the physical universe that are at the root of the engineer's skill. The methods of mathematics and science discipline the mind to think rationally.

On the other hand, engineering practice is about creation, about making things that are added to the community for the benefit of its members. Students who intend to practice engineering need more practical skills to discharge their obligation of and to the profession. These skills are those required to carry out engineering tasks in modern business and technical settings, and include the ability for self-guided lifelong learning, designing, technical communications, project management, critical thinking, creativity, and problem-solving. These are the skills that make engineers the people who do things, and create things.

Baccalaureates would ideally possess an understanding of both the applied sciences and the practical skills in some suitable balance. Each university seeks its own balance, measured with respect to the institution's mandate and resources.

However, it is becoming ever more difficult to maintain the balance between deep theoretical and practical skills. Modern society calls for more generalists; persons able to work comfortably in teams, on diverse problems that are broader in scope than in the past. They work at a "systems level", relying on specialists to cover specific details. They must address the broad and long-term impacts of their work on society and the environment. They spend a significant portion of their time designing or doing design-related work. Based on my experiences at four universities, while employment opportunities are described as requiring specialized technical skills, those who get hired - especially freshly minted baccalaureates - seem to be those who demonstrate a capacity for generalism.

Our technological sophistication, brought about by the vigorous development of the applied sciences (especially since the end of the Second World War) has led to an understanding of the interconnectedness of all the systems we create and use. As the very tall management "pyramids" of past decades have flattened out, micro-management of technical activities has given way to a more open, selforganizing approach. Even in the North American automotive industry, arguably one of the most conservative industries in the world, outsourcing of whole systems rather than individual parts is becoming a standard practice. Tier 1 auto suppliers are becoming systems developers (with inherently strong design aspects), something for which history has not prepared them very well. Systems interactions determine product performance at least as much as the performance of individual components. Specialists lack the background to treat the systems issues, and generalists lack the background to treat specific component issues. Specialism tends to require clear separation of duties, leading to tall management structures and substantive barriers between disciplines. This goes against the current industry trends.

Multidisciplinary teams use concurrent engineering practices to blend expertise from diverse fields. Students with deep knowledge of the applied sciences, typically taught as a solitary skill, are not prepared for such a working environment. At the same time, the increased complexity of the technologies themselves require students to have a better understanding of the basics of science and mathematics, from which all these new and emerging technologies come.

Given the limits imposed by the generally accepted structure of engineering education (i.e. undergraduate programs limited to four years in length) and the constant need to be cost-effective, it is more and more difficult to find and maintain an appropriate balance between the applied science aspects and the engineering aspects.

Others have suggested solutions like lengthening undergraduate programs to, say, five years. While this would alleviate the problem at least for a while, I do not believe this is the best solution. Eventually we would hit the same problem again because a five-year program would allow greater opportunity to add even more material into the curriculum without necessarily changing the underlying approach to the selection and delivery of that material.

Furthermore, in all discussions or reports on this matter of which I am aware, the student community 
has been treated as a homogeneous group, each with roughly the same general aptitudes and characteristics of the rest. However, on graduation, students will be hired into one of two broad classes of jobs: jobs in design or production, and jobs in analysis or research and development. This is born out by anecdotal evidence from my own experience and the experience of some of my colleagues: students who excel in analytic work do not necessarily do well in teambased, design-oriented exercises - and vice versa. (Example: a student of mine, who graduated with a $4^{\text {th }}$ year average GPA of 4.33 - 100\% - and who has excelled in industry since graduation, barely managed to remain academically "clear" in his first two years. Coincidentally, the first two years consist largely of science and math, whereas the senior years are mostly engineering.) The right problem, as I see it, is to develop an educational system that caters to both these two broad groups of students.

\section{A Possible Solution: separating Applied Science from Engineering}

The problem of balancing program needs must be based in part on the expected roles our students will assume in industry. In particular, I see the lines between applied science and engineering becoming more and more blurred in academia, while they remain quite crisp in industry. Given this, we should consider a clearer distinction between degrees in applied science and degrees in engineering, both at the undergraduate and graduate levels.

By separating applied science from engineering, recognition is given to the two basic job types that exist in industry: analysis and synthesis (or, correspondingly, specialism and generalism). Neither can exist without the other, and there must be some overlap in how curricula are delivered. We can also see this as providing trained personnel to each of the three categories of research noted in Section I (basic research, project research, and consulting) that are better prepared for each specific category. The separation I propose is more a matter of emphasis than just a clean and total break. Students in both applied science programs and engineering programs would have to have a solid foundation in the sciences and mathematics. But that foundation would be oriented towards the eventual goals of the degree, and the manner in which those foundations are delivered would differ as well.

In applied science programs (as distinct from engineering programs), students must attain a high level of scientific expertise, an understanding of how the universe functions, of the laws of nature, and the rules of mathematics. The tools of their trade are the scientific method and the techniques of mathematics and, increasingly these days, computer science.

In engineering programs, on the other hand, one should expect a focus on the practical side of using science and math as tools, but without the same depth of understanding that the applied scientists have. The engineer must be able to appreciate the importance of balancing safety, cost, quality, weight, durability, and usability when developing a product; this is not just a matter of science and math. The engineer may rely heavily on the specialised expertise of the applied scientist, but will also bring his own distinct expertise to the problem.

Most importantly, the applied scientist is by definition not interested in changing reality, only in studying, explaining, and predicting it. The engineer, on the other hand, accepts the explanations and predictions of the applied scientist, and then acts to change reality to achieve some goal. Coarsely put, engineers design but applied scientists do not. The participatory nature of engineering distinguishes it at the most fundamental level from applied science.

Our educational system ought to reflect this distinction crisply. Instead, we burden students with having to learn scientific and mathematical knowledge that is not necessary for engineers to practice engineering, even though most baccalaureates go into practice, not research. Similarly, we burden students with having to learn engineering knowledge that is not necessary for applied scientists.

I believe the best solution is to define two streams of education, both leading potentially to a doctorate. The applied science stream would lead to a $\mathrm{PhD}$, the goals of which are to prepare candidates for a career in academia: grantsmanship, teaching, and research. The engineering stream would lead to a DEng, holders of which will have the technical, design, and management skills to work at the executive levels in industry, business, and government.

At the undergraduate level, the distinction between BASc and BEng degrees would have to be recognized by the CEAB and taken into account in accreditation criteria. The BASc degree would focus on the applied sciences and mathematics while the BEng would focus on product development, design, manufacture, and the "soft" skills that are becoming hard requirements in industry (e.g. teamwork, communications, and management and business skills). The applied scientist would be the analyst; the engineer would be the synthesist. The applied scientist would expand the fundamental working knowledge of technology and 
engineering, and the engineer would apply that knowledge to the development of new products and services. The current curriculum places sufficient emphasis on math and science for applied science students, but at the expense of the broader, industrially relevant perspective needed by engineering students.

Consider the recent popularisation of closed-loop design/analyse cycles provided by many popular CAE software vendors. The kind of situation that is becoming the industrial norm is described in such articles as [1]. There, finite element programs are mentioned together with spreadsheets - not because of any similarity in complexity, but because they are both thought of black-box software that any reasonable engineer, with or without a computer background, can use. Modern FEA software, when used correctly, requires input given as geometry, loads, and engineering constraints. In conventional problem domains typical in industry settings where baccalaureate engineers work, there is rarely need for a user to understand the mathematics of finite elements. However, in speciality areas, cutting edge research, and design and development of new analysis software (i.e. the applied sciences), the need for particular expertise and deep mathematical understanding is greater than ever.

Given such a dichotomy, it is clear that CEAB criteria should be different for the two degrees. While obviously there should be differences in how the academic units (AUs) are calculated, there should also be differences in how material is delivered. While it is a highly contentious issue, I believe that engineers make the best engineering instructors. Sciences, maths, and technical communications should be taught to engineering students by engineers because engineers know better than any other professionals how to make pertinet subjects that may not immediately seem so to students. We (instructors) must remember that our perspective is significantly different from those of students. We have the benefit of years of practice with the applied sciences that students lack. One of the most persistent complaints by students in junior years is that the applied sciences are taught in a manner that do not integrate well with students' existing "knowledge bases". The result is poor retention of material. Engineers know better how to relate the applied sciences to the kind of situations that students already understand. As such, the material is learned more deeply.

Furthermore, an opportunity exists here to address the problem of "siloing" in engineering programs. From the point of view of applied science, it is perfectly reasonable to arrange academic programs by discipline as we have them today. Engineering, however, is inherently multidisciplinary. In practice, mechanical engineers work with many other kinds of engineers and non-engineers, yet in engineering programs we keep (with only rare exception) the mechanical engineering students separate from, say, the electrical engineering students. This is a very naive and unsophisticated perspective on engineering education. One of the advantages of teamwork is the synergy that can develop between team members that leads to significantly enhanced productivity. The whole (the team) is greater than the sum of the parts (the individuals ), and the curriculum must designed to reflect this across and not just within, the disciplines.

At the Master's level, a new meaning must be given to the MEng degree. As things stand today, many MEng programs are looked upon by university faculty members as "MASc light", a degree for those unwilling or unable to undertake the rigors of a MASc. Sometimes, a MASc student found to be unable to complete a program of study may be "demoted" to MEng status. I strongly oppose such a perspective. The MEng degree should be regarded as a specialisation for industrial practice, while the MASc remains oriented to research. In too many schools, MEng and MASc students choose courses from the same list, even though the courses are usually intensively research-oriented, with heavy doses of advanced science and math. This is inappropriate for the MEng students, who also must often take more of these courses than do MASc students.

Furthermore, the courses are in many cases developed on the basis of the research capacity of the faculty available to teach it. This means the curriculum is largely disconnected; students are left to knit the material into a meaningful whole on their own. At the Bachelor level, most universities have a thesis or design capstone that gives an opportunity to bring together all that knowledge. But at the MEng level, there is no such opportunity: the MEng project is often just a research project without the research component.

Instead, the MEng course load should include courses in business and finance, product development and design, advanced manufacturing, and project management. MEng level courses should be specified according to a detailed plan of expectations developed by the institution offering the degree. Every course offered must provide a distinct piece of the puzzle for students. The MEng project should involve the practice of the skills expected of a "Master of Engineering" (rather than of Applied Science), and should include a substantial internship or practicum in 
some appropriate industry. MEng students are often able to execute modest amounts of research, and so the MEng project should lie somewhere between Brzustowski's project research and consulting work. An MEng graduate could then use his project as a clear demonstration to prospective employers of the capacity to execute projects of substantively highly complexity than a Baccalaureate.

The suitably prepared MEng graduate should have the academic background to support the graduate's entry directly at the supervisory or project management level in industry. This is simply not possible given the "conventional" approach in most schools to the MEng degree.

Finally, at the doctoral level, I believe we need to introduce a new degree, the DEng (doctorate of engineering). Such degrees already exist in various countries (e.g. U.S., Australia, U.K.). Under the scheme I am suggesting, the DEng would be parallel to the $\mathrm{PhD}$ and subsequent to a MEng.

Most students who pursue a doctorate do so with the intention of entering academia, or pursuing extensive research in industry and government. $\mathrm{A} \mathrm{PhD}$ in engineering is of relatively little use in industry otherwise. However, the DEng degree would be specifically targeted at industry. While the goals of the $\mathrm{PhD}$ would be independent research, teaching, and grantsmanship, the goals of the DEng would focus on preparing individuals to assume positions in executive management and government, and assume leadership roles in technology management and development (as opposed to "research") and policy-making. A DEng would also open a new market: students with a MEng who would like to further refine their knowledge and skills, but cannot pursue a PhD without first doing a MASc. The DEng would also help promote the engineering profession by creating a stream of extremely qualified personnel that are able to assume roles of high visibility and impact.

\section{Benefits of separation}

Clearly there is a cost associated with this proposal. New accreditation requirements and curricula will have to be developed. Phasing in a proposal such as this one will take many years. However, there are many potential long-term benefits also.

By distinguishing more clearly between applied science and engineering, students will be better prepared to participate fully in whatever sector they choose. Both industry and research will benefit because students will receive more pertinent and directed education. In the long run, engineering capacity in practice should improve. With clearer goals, represented by the tighter scope expected of graduates, curricula could become better integrated. Graduate programs, more tightly focussed than those currently available, will essentially provide students with more time to work on specific outcomes. In the applied science stream that leads to a $\mathrm{PhD}$, students will have more opportunity to learn the skills expected of top-flight re-searchers and teachers. In the engineering stream that leads to a DEng, students will be in a better position to climb the corporate ranks more quickly and effect greater change.

Separation of applied science from engineering does not mean that there will be no opportunities to collaborate. Applied scientists pursue new technological advances that lead to new product development possibilities; and problems arising from product development would motivate further scientific research. At the same time, the adoption of new design and manufacturing technologies by industry and the evolving sensibilities of society lets engineers inform applied scientists on potential directions for their research. Each of the two streams both depends and is dependent on the other. For example, consider the development of a new lie detector as reported in MIT Technology Review [2]. The detector uses infrared light to sense blood flow in the pre-frontal cortex of the brain, in which activity is greater when lying than when telling the truth because lying requires greater cognitive effort. Here, development of an extremely useful product has occurred in response to a significant amount of applied scientific work. Both the depth and the breadth of the knowledge that is required to understand this crossdisciplinary application are substantial. "Lone geniuses" (once referred to as "renaissance men") with the right combination of knowledge and skills are increasingly rare. It is more likely that applied scientists and engineers, each skilled in their own fields and working collaboratively, would have more luck working on such problem areas. But this assumes each has a specific kind of expertise that the other does not have - a situation not possible in our current educational environment.

Also, separation does not imply a "two-tiered" educational system. Applied science programs and engineering programs must be equal partners, opposite sides of the same coin. The recognition of the diversity of roles that the applied sciences and engineering play does not imply a relative value judgement. By separating engineering from applied science, there is also opportunity for educational collaboration between Universities. For example, in 
Toronto, the University of Toronto could offer applied science degrees while Ryerson University could offer engineering degrees. Students from both schools could collaborate on projects that have both research and practical aspects. Joint research grants could be proposed where the distinction between the roles of partner Universities is much crisper and easier to manage and justify. Joint courses in specific topics can be offered thus providing a new channel for cost sharing of delivery.

\section{Implementation}

Assuming any consensus is achieved around this or a similar proposal, governmental and regulatory bodies will have to take the lead to bring such a proposal to fruition. Clearly, Canadian academia would have to change substantially to accommodate this proposal or something similar. The CCPE should strike a working group composed of representatives of the $\mathrm{CEAB}$, as well as researchers and teachers from the Universities and industry representatives as well, to build a detailed proposal and implementation plan for such an undertaking. This activity should be coordinated with all graduate school accreditation bodies (such as OCGS in Ontario).

Defining the scope of each of the six different university degrees posited in this proposal would be the first and most important activities. Such definitions would be based on expectations arising from presumed activities of the degree holders. Given these expectations, major curriculum areas can be defined and eventually fleshed out.

A key feature of this approach in my mind is the extent to which mathematics and the natural sciences are taught in the undergraduate program. Current undergraduate engineering programs contain a great deal of math and science, and the science is commonly taught with respect to the mathematical models of those physical phenomena.

I believe that mathematics and science are fundamental to engineering because they teach students how to think in a particular structured and clinical way that is of benefit to practicing engineers. However, I also contend that, in engineering, this scientific attitude to problem solving is more useful than the actual equations and physical phenomena that are studied. Once in practice with a Bachelor's degree, one is not faulted for having to check a reference text for particular equations. One must, however, understand what the equation means in practice. Should a baccalaureate engineer (as opposed to an applied scientist) be able to solve Schrodinger's equation? I contend that the answer is no (in most cases - electrical/electronic engineering being a potential exception).

We may also invoke the Pareto Principle, which suggests that $80 \%$ of the performance of a product (with respect to cost, quality, function, safety, etc.) is set by the decisions taken in the first $20 \%$ of the product development process. This is squarely within the purview of design, and rarely requires the detailed level of analysis often delivered in undergraduate curricula (always with respect to engineering versus applied science). In other words, the decisions that make or break a product in practice involve design engineering and a number of other issues (e.g. project management, marketing, etc.) in which the design engineer will be involved. Math and science play only a supporting role here.

Furthermore, design comes causally before analysis. However, students asked to analyze without having any sense of why those designs exist are caught in a conceptual vacuum. They cannot ask why a truss or a circuit or pipeline is shaped as it is because that information is simply unavailable. Furthermore, many instructors discourage students' asking about how the products described in analysis questions were designed. This fosters a learning environment that disengages students from asking the questions that are fundamental to solving real, engineering problems. A truss might by sub-optimally designed at first glance but the design may be the best possible response to a particular operational environment. Yet such information is woefully lacking in typical texts and courses. After four years of such an environment, it is no small wonder that many students find senior design courses so difficult. They have, in essence, had that capacity to synthesise beaten out of them.

This impacts the presentation of curriculum. For a degree in applied science, there is nothing wrong with having the junior years heavy with math and science elements. However, in engineering, I believe that the junior years should be heavy with design and manufacturing elements, and math and science should be introduced only as needed (a so-called "just in time" learning model).

This impacts on implementation because schools offering programs adopting a just-in-time approach for teaching math and science will have to find instructors capable of delivering not only engineering subjects, but also the math and science components required by those subjects.

Another implementation issue involves the CEAB's current allotment of academic units (AUs) for lectures and labs. As currently implemented, a one hour lab is 
only worth half as many AUs as a one hour lecture. While there does exist a "workaround" (the use of the so-called proportionality factor $k$ ), the fact that it is a workaround and not an embedded feature of the accreditation mechanism makes lab-based work seem relatively unimportant compared to lecture-based work. This matters in engineering curricula (as opposed to applied science curricula) because engineering is first and foremost about doing, about "getting one's hands dirty". The CEAB's current policy suggests that lectures are better media for learning than labs (and tutorials, and studios, and all other forms of delivery). This is, quite frankly, a rather old-fashioned approach.

If new requirements were to be developed for engineering programs as distinct from applied science programs, it would be essential to make lectures and labs/tutorials/studios identically weighted in AUs. Indeed, one might even consider making engineering "studios" (essentially, extremely short practicums) to be worth even more than lectures. This, however, may be too radical an innovation to attempt at this time.

In summary, the following describes the basic structure and goals of the proposed new set of degrees.

\section{For applied science degrees:}

BASc: basic grounding in mathematics, quantitative and applied sciences, basic research methods.

MASc: closely guided independent research; detailed study of mathematics and applied sciences.

PhD: nearly independent research, grantsmanship, and teaching; deep learning in one applied science or branch of mathematics.

For engineering degrees :

BEng: basic grounding in mathematics \& qualitative science as applied to engineering practice, design and manufacture.
MEng: closely guided "project research" in design and manufacture; deep learning in project management and leadership.

DEng: nearly independent development of a whole product "from scratch"; deep learning of impact of technology on economy, policy, and quality of life.

\section{Conclusion}

I believe that engineering education is being stressed by an ever-increasing tension between the need to embed more applied science content as well as more design-related and "soft skill" content. This tension could cause irreparable harm to the profession if it is not addressed soon. One way to do this would be to develop two parallel streams of degrees - one for applied science and another for engineering - each with their own curricula and accreditation requirements. The tension would be relieved, but also more space would be created in each stream to further refine students' capabilities. It may be difficult to implement such changes in the modern conservative climate in engineering education. However, I believe there would be long-term benefits from such a change. These changes could take a long time to design and implement properly, but as they say, the longest journey begins with a single step. Let us start walking together, soon.

\section{References}

[1] J. Thilmany, Expert Built-in. ASME Mechanical Engineering, 123(10):70-72, 2001.

[2] -, The Deceit Detector. MIT Technology Review, 106(5):66-69, 2003. 